\title{
Informação em saúde: produção, consumo e biopoder
}

\author{
Information on health: production, consumption and biopower
}

Cléber Domingos Cunha da Silva ${ }^{1}$

${ }^{1}$ Serviço de Educação Permanente, Hospital Municipal Dr. João Elísio de Holanda. R. Uruguaiana 1120, Pan-Americano. 60.440-370 Fortaleza CE. domingos.cleber@hotmail.com

\begin{abstract}
This article seeks to elicit misgivings regarding the value attributed to medical truth found in the biomedical literature. The issue of the protection of sexual practices was taken by way of example and the works of thinkers like Nietzsche, Baudrillard, Bourdieu, and especially Michel Foucault, were consulted. This was done in order to consider that the elaboration and use of health information can be interpreted as a practice constituting a policy that dynamically inspires both experts and non-experts on medical truth, constituting a morality that is based on the production and consumption of this truth. It is a policy that Foucault called biopolitics, able to establish ways of living where the exercise of thought does not seem to be so "rewarding," where practices of command and obedience are mediated by health information. In this perspective, physicians and non-physicians have been seduced by the desire to attain the truth, such that the commitment of everyone is seen to concentrate on the production and use of statements that they believe can prolong life and save from getting sick. These are discourses cultivated in the market of a media-dominated society in which individuals controlled by information produce subjectivities that are anchored in the medical-capital truth binomial.
\end{abstract}

Key words Information on health, Biopower, Medical truth, Biomedical literature
Resumo Este trabalho objetiva suscitar desconfianças ao valor atribuído à verdade médica presente na literatura biomédica. Tomou-se como exemplo a temática da proteção das práticas sexuais e recorreu-se às obras de pensadores como Nietzsche, Baudrillard, Bourdieu e, principalmente, Michel Foucault, a fim de pensarmos que a elaboração e o emprego de informações em saúde podem ser interpretados como práticas constitutivas de uma politica que articula dinamicamente peritos e não peritos à verdade médica, constitutiva de uma moralidade que se apoia na produção e consumo dessa verdade. Uma política, denominada por Foucault de biopolítica, capaz de estabelecer modos de viver onde o exercício do pensamento parece não ser tão "recompensador", onde práticas de mando e de obediência a si são mediadas pela informação em saúde. Nesta perspectiva médicos e não médicos foram seduzidos pela vontade de atingir a verdade, de modo que se verifica o empenho de todos na produção e consumo de enunciados que acreditam poder prolongar a vida e salvá-la do adoecer; discursos cultivados no mercado de uma sociedade midiática, onde o controle dos indivíduos pela informação produz subjetividades que se ancoram no binômio: verdade médica-capital.

Palavras-chave Informação em saúde, Biopoder, Verdade médica, Literatura biomédica 


\section{Introdução}

Se considerarmos que existem pessoas que não têm acesso às informações sanitárias, sequer aos profissionais de saúde e a certos tratamentos, de que existem até mesmo profissionais de saúde que não recebem informações atualizadas sobre tratamentos de doenças e que não têm acesso a tecnologias para um melhor diagnóstico da doença, como pensarmos, a partir destas condições, em uma vida saudável? Ora, o não acesso a tudo isso pode se constituir numa desproteção. Essa é a ideia do risco. O risco é a possibilidade de prejuízo, é o conceito organizador da maioria das práticas médicas e está presente em quase todas as publicações leigas e médicas. Basta pensarmos que os cadernos sobre saúde, presentes em jornais comerciais são, sem dúvida, inteiramente voltados para o risco ${ }^{1}$.

Condutas consideradas "não esclarecidas", que poderíamos denominar de condutas "médico-transgressivas", como por exemplo, fumar, ter relações sexuais sem proteção, ingerir alimentos gordurosos e sedentarismo, acabam provocando da parte dos profissionais de saúde e de pesquisadores, uma inflação de enunciados explicativos, associando estas condutas a experimentações de adoecimento. Assistimos à instauração e ao desenvolvimento de uma concepção de que é necessário informar a sociedade para que os indivíduos mudem seus hábitos, seus comportamentos sexuais, suas práticas alimentares e seus modos de viver. Trata-se de uma ideia policial, de controle social, nascida dentro de uma batalha para exercício do controle.

Um dos objetivos do repasse de informações em saúde aos indivíduos é fazer com que estes se tornem hábeis em gerenciar riscos em suas vidas, no sentido de reduzirem as chances de experimentarem danos à saúde. Desse modo, os "informados”, cada um com seu programa pessoal, aprendem a administrar a empresa da vida ao comerem, beberem, amarem, andarem, dirigirem, investirem, jogarem, economizarem, estudarem, trabalharem, lutando por uma condição de saúde e felicidade em um mundo do qual estão convencidos de que é incerto.

$\mathrm{Na}$ sociedade do risco ${ }^{2}$ é inadmissível que o perigo não seja conhecido. Verificamos que um dos objetivos daquilo que Foucault denominou de biopoder é fazer com que os indivíduos, a massa de modo geral, sejam atingidos pelos processos de disseminação e internalização do saber biomédico.

Em sua obra denominada Risco, Adams faz menção do Homo prudens, que ele chama de ho- mem do risco zero, "a personificação da prudência, da racionalidade e da responsabilidade" ${ }^{\text {. Ora, }}$ o Homo prudens seria na perspectiva de Foucault, o homem que luta constantemente para não errar, aquele que busca internalizar os ensinamentos, as dicas, os avisos de perigo, as normas do bem viver e que toda vez que falha, confessa sua falta.

Diferentemente daquilo que se verificou por dezenas de anos na sociedade ocidental, em que as faltas eram confessadas pelo exercício de uma oralidade: como a do crente ao sacerdote, dos filhos aos pais, dos estudantes a seus mestres, do infrator ao juiz, o que temos na contemporaneidade é a confissão do erro mediante os registros.

Segundo Adams, quanto mais riscos uma pessoa corre, maior em média serão as recompensas e também as perdas. Se tomarmos o caso do tabagismo e os riscos a ele associados, temos desde o câncer de pulmão até a insuficiência respiratória, a disfunção erétil, as mutilações de membros e um enorme custo para o sistema público sanitário. E é justamente visando à redução dos gastos públicos com os infortúnios decorrentes das práticas de danação, que o Estado adota a estratégia de informar sobre saúde aos seus cidadãos.

O Estado acredita que quanto mais bem informadas são as pessoas sobre o perigo e quanto mais hábeis elas forem em seus julgamentos, menor será a exposição que farão às circunstâncias, aos fatores de risco. Só que a segurança, dirá Foucault, "a segurança é uma certa maneira de acrescentar, de fazer funcionar, além dos mecanismos propriamente de segurança, as velhas estruturas da lei e da disciplina"3. Sob a perspectiva foucaultiana, sabemos que a circulação da verdade, bem como sua disseminação, exercem efeitos de subjetivação. Basta pensarmos que estas informações serão capazes de constituir uma moralidade, pois são compreendidas como portadoras de um valor, de uma norma que não pode ser contrariada, negligenciada e muita menos desobedecida. Trata-se de uma informação cujo não seguimento articula o indivíduo à doença, já que o seu não cumprimento traz para o infrator a "promessa" de padecer do infortúnio do adoecimento.

Mas essa subjetivação vai se dar na relação entre o sujeito e uma racionalidade, melhor dizendo, entre o sujeito e uma verdade. Uma verdade que pode ter sido adquirida pelos processos de escuta e/ou de leitura, ou que pode ser aquela somatória de experimentações. Assistimos à constituição, em nossos dias, do estabelecimento de uma sociedade que é alvo de um contínuo 
assédio de uma vontade de educar, esclarecer, informar, saber, de fazer circular e de disseminar questões relacionadas à saúde, ao cuidado com o corpo, à preservação e à conservação da vida. Uma busca frenética pela longevidade, pela saúde e pela preservação do corpo. Porém, esse movimento não tem à sua frente médicos ou cientistas isolados.

Médicos e não médicos, doentes e não doentes, todos tornaram-se alvos de uma reciclagem cultural em saúde, mas também de uma reciclagem do corpo. Estamos diante de fenômenos que caracterizam o que Jean Baudrillard denominou de Sociedade de Consumo, uma sociedade que se tornou doente ${ }^{4}$. Trata-se de uma profunda liturgia da solicitude por saúde. Uma solicitude que Baudrillard caracteriza como ambígua, já que, primeiramente, assume características de "ter cuidado com", "tratar maternalmente", mas que assume sentido de demanda, com solicitação de uma resposta, uma atenção, uma adesão. Assim sendo, a sociedade converte-se em "consumidor", objeto sobre o qual incide o duplo empreendimento de uma informação que é capaz de exercer um controle "político" mediante a solicitação que objetiva regular as mais íntimas motivações dos indivíduos. Por isso, o discurso terapêutico do qual os profissionais de saúde consideram-se os mais fiéis e legítimos portadores, acaba por convertê-los em agentes publicitários.

Os indivíduos ao buscarem os médicos para narrarem suas queixas, estariam, nessa perspectiva, buscando a segurança que todo bom cliente da sociedade de consumo objetiva. Uma segurança que encontra sua certeza na aquisição dos conselhos fornecidos por tais agentes publicitários, veiculados nos mais diversos meios de comunicação. Enfim, a promessa de saúde para o corpo é um desencadeador de venda, uma enzima mercadológica. De modo que se pode afirmar que uma das principais motivações para a produção de verdades médico-científicas na contemporaneidade é a preocupação com o corpo, seja o do indivíduo, seja o da população. É em torno desse corpo que se constituiu, por exemplo, uma política que impõe a necessidade de fabricar verdades e de fazê-las circular, uma política que recompensa os que mais as produzem e que as fazem chegar até os microfilamentos do tecido social. É a usina de produção de verdades encontrando na saúde do corpo sua matéria-prima.

Estamos numa sociedade onde "não adoecer" tornou-se a norma, valor "absoluto", regraouro. Em outras palavras, o anormal é todo aquele que adoece. E para isso, cada um deve ser ades- trado, treinado, capacitado, instruído e corrigido de modo ininterrupto, de modo que não adoeça, pois a doença deixou de ser concebida como um fenômeno inerente aos processos vitais e se converteu em algo a ser banido da vida. É o estabelecimento da saúde como um ideal, como um valor, e isso é, em Nietzsche, decadência ${ }^{5}$. Não que a busca pela saúde do corpo seja algo criticado por Nietzsche, ao contrário; mas a elevação da saúde à condição de valor é tão somente o sintoma de que o homem, na busca de sentido, sempre estabeleceu ídolos e altares para suportar sua condição de mortal.

\section{Biopoder e informação em saúde: o caso das Doenças Sexualmente Transmissiveis (DST)}

Foucault demonstrou como a medicina, a partir do século XVIII, veio a conceber o corpo como uma realidade biopolítica ${ }^{6}$. Em grande parte de suas obras Michel Foucault assinalou pontos a partir dos quais fundamentou o que ele mesmo denominou de biopoder, algumas de suas práticas e as primeiras áreas de sua intervenção: a natalidade, a morbidade, as incapacidades biológicas, os efeitos do meio. De tudo isso, o biopoder fundamenta seu saber e define seu campo de intervenção.

Sendo assim, dentre os fenômenos de interesse da medicina na contemporaneidade, estão as práticas sexuais desprotegidas, consideradas como um dos principais fatores responsáveis pelo surgimento de Doenças Sexualmente Transmissíveis (DST), importantes causas de óbitos. Assim, os discursos dirigidos aos indivíduos e às populações, produzidos pela medicina e disseminados pelos múltiplos meios disponíveis, no intuito de que as relações sexuais sejam feitas com proteção, ou seja, de que se use camisinha, são discursos biopolíticos ${ }^{7}$.

$\mathrm{Na}$ perspectiva do filósofo francês Michel Foucault, o sexo tornou-se um objeto político e, por isso, alvo de gestão. Com o advento da SIDA (Síndrome de Imunodeficiência Adquirida) e o número gigantesco de óbitos por ela ocasionados, o sexo e as práticas sexuais tornaram-se alvos privilegiados da biopolítica em sua tarefa de modificar e fazer a gestão da vida, em baixar os níveis numéricos de adoecimento. Em suma, em seu engajamento na busca da longevidade, no encompridamento da existência humana.

Brilhantemente, Foucault apontou a desqualificação progressiva da morte como a mais clara manifestação do biopoder ${ }^{7}$. A morte, que foi 
durante milhares de anos um dos principais objetos de ritualização pública, deixou de sê-lo desde o fim do século XVII, e hoje, como nunca, constitui objeto de negação. É por isso que nas sociedades contemporâneas, tanto os indivíduos com vida sexual ativa como os que têm potencialidade de a "ativarem", são alvos de disciplinamentos e regulamentações, são indivíduos-alvo do convencimento de que devem utilizar medidas de proteção, convocados a se reconhecerem como corresponsáveis pelo seu estado de saúde, pela gestão de sua sexualidade, de seu corpo e de sua existência. A responsabilidade pelo cuidado está passando das figuras do médico e dos demais profissionais de saúde, reconhecidas autoridades do saber, para o próprio indivíduo. A vigilância sobre a prática sexual passa a ser exercida pelo próprio indivíduo, o responsável direto pela sua vida e por sua morte.

Assim, a forma do poder exercida pela indução de uma vigilância contínua do indivíduo sobre si mesmo encontra na informação que adverte sobre riscos um ininterrupto convite à moderação ${ }^{3}$. Um convite, inclusive, que está sendo fortalecido com os avanços da biotecnologia. Pois, com o mapeamento do genoma humano e sua junção com a epidemiologia, nasce uma medicina que é preditiva, não endereçada aos doentes, mas aos indivíduos sãos. Com os dados sobre o genoma serão reveladas as pré-disposições dos indivíduos a contraírem doenças e as pessoas tornar-se-ão doentes antes da hora ${ }^{8}$.

Se uma característica fundamental da "sociedade de controle" é a nova relação entre atores leigos e peritos, em que a opinião ou o conselho de algum cientista sobre algum tema (ex.: dieta, saúde, óbitos) rapidamente passa para a consciência e à rotina diária dos indivíduos através dos meios de comunicação, a necessidade de se empregar a camisinha torna uma espécie de carrochefe dos discursos biopolíticos presentes nas publicidades sanitárias. O que se objetiva concretamente com tais discursos é que a conduta dos indivíduos e da massa se torne cada vez mais governada pelo consumo de um conhecimento considerado reflexivo, de modo que se desloque ou se esvazie aqueles discursos incorporados pela tradição ou pela força do hábito.

Tomando ainda como o exemplo o caso da proteção das práticas sexuais, vemos a pretensão da medicina em permear as mentes das pessoas com seus achados, na expectativa de que a concepção de risco que ela produz torne-se a base para a gestão da vida humana: "O mais seguro de todos os comportamentos sexuais, como en- sinam muitos sistemas religiosos e éticos, é a abstinência. $\mathrm{O}$ único material preventivo que uma pessoa precisa é aquela droga maravilhosa, o 'autocontrole'. Não saia de casa sem ela. [...] Depois que o cérebro informado, pensativo e bem controlado estiver engajado, pode não haver necessidade da 'reflexão de látex"'9.

Com esta afirmação, Jenkins reafirma a clara necessidade de disseminar, de fazer chegar até o ponto mais extremo das relações sociais aquelas informações relacionadas às descobertas, aos novos achados em saúde, capazes de promover mudanças comportamentais que garantam uma "vida saudável". Para ele, como para todo o sistema sanitário da atualidade - e isso desde o século XVII -, a vida e a morte estão na dependência do conhecimento. Um conhecimento qualificado, revestido de cientificidade, que é preciso fazer circular, fazer chegar até as extremidades do tecido social, e cuja adesão ao mesmo poderá defender a sociedade, preservar a vida. Quando isso acontecer, segundo Jenkins, quando o cérebro estiver plenamente imerso, banhado nesse oceano de informações, não haverá a necessidade de dizer: "use a camisinha, use o "látex"”.

\section{Verdade médico-científica e moral}

No presente momento, com a disponibilização de informações médicas e sanitárias na Internet, por exemplo, as pessoas estão trocando o encontro corpo a corpo com o médico por consultas a revistas, jornais e recomendações presentes em sites médicos. Só que a escuta e a fala, procedimentos básicos do processo ensinoaprendizagem, não estão presentes na maioria desses espaços, condicionando o leitor a fazer interpretações por si mesmo. Nesse sentido, temos uma nova moral em andamento, que se caracteriza pelo controle do corpo pelo próprio indivíduo ${ }^{10}$.

Trata-se do estabelecimento de uma relação de comando e de obediência por si e $a$ si, mediada pela informação, pelos aconselhamentos, pelas dicas que proliferam no mercado. Essa moral em andamento, em processo veloz de cristalização, sedimenta a sociedade que Deleuze denominou de controle. É o controle sobre si mesmo mediado pela informação médica, é a afirmação sofisticada de um ascetismo ${ }^{11}$.

O consumo das informações é objetivado com a finalidade de que esse controle ínfimo, mas eficiente, seja efetuado. Atingindo os mais distantes pontos do tecido social, as informações médicas vão exercer efeitos sobre indivíduos que 
nunca estiverem em contato, corpo a corpo, com um profissional de saúde. Doravante, não será necessário ir ao médico para saber o que fazer para não adoecer, ou para se curar de alguma doença; basta estar conectado à $\mathrm{TV}$, ao rádio, às mídias em geral.

Com a sociedade midiática, o que observamos é que, para cada dimensão da existência, são estabelecidos novos grupos de códigos médicos a serem seguidos. Para a saúde, para a nutrição, para a beleza, para o amor, para o trabalho, para o lazer, para o vestuário, para a moradia, para a educação etc. Mas, esse controle sobre si mesmo não tem nada a ver com uma relação de independência, senão de dependência com relação ao especialista. Agora, à luz dessas informações em saúde, as pessoas ao examinarem suas consciências vão poder dizer ao médico o que fizeram e o que não fizeram, as situações de perigo a que foram expostas, as transgressões e os progressos, ou seja, vão ancorar ainda mais o exercício ascético de submissão de si mesmos ao perito, à verdade.

E será a partir desse exame de consciência que o indivíduo vai formar, de si, a cada instante em que se consulta, em que lê, em que é informado, certo discurso de verdade. E será na relação que estabelece entre si e esses discursos, que vai extrair um tipo de verdade que o ligará àquele que o conduz. Trata-se de um processo de individualização que, como diz Foucault, "vai se dar não pela designação, pela marcação de um lugar hierárquico do indivíduo. Ela não vai se dar, tampouco, pela afirmação de um domínio de si sobre si, mas por toda uma rede de servidões, que implica em a serviço geral de todo o mundo em relação a todo o mundo, e ao mesmo tempo a exclusão do egoísmo como forma central, nuclear do indivíduo. É portanto uma individualização por sujeição [...] é uma individualização que não vai ser adquirida pela relação com uma verdade reconhecida, [mas] que, ao contrário, vai ser adquirida pela produção de uma verdade interior, secreta e oculta"12.

A informação em saúde é um instrumento de controle, e informar é uma estratégia para regular a vida dos indivíduos. Ela é a governamentalidade direta do médico, um meio de medicalizar permanentemente a sociedade; é a via pela qual a verdade fabricada será posta em circulação e se imporá em nome e em função da racionalidade sanitária. Logo, estamos falando de um mundo em adoecimento, indefinidamente, e nos detalhes, através da informação. Mas, um mundo que é dilacerado pela sublevação dos "desobedi- entes", que introduzem nele a dimensão da "subjetividade".

É possível dizermos, a partir da perspectiva biomédica, que a ignorância relacionada ao não saber cuidar do corpo, para que este não adoeça, se trata de uma condição de negação da vida, no sentido de que a vida humana, que é vulnerável, encontra-se desprotegida dada a ausência de um determinado tipo de saber. Essa condição de vulnerabilidade será mais agravada se esse estado de ignorância for de uma profundidade tal que nem sequer for percebido, isto é, se não se sabe que se ignora, se não se sabe que não se sabe.

Essa ignorância pode se manter, na vida de algumas pessoas, até o final de sua existência. Por outro lado, suas opiniões e crenças sobre como viver e agir, diante das enfermidades e/ou doenças, podem se manter como eficazes e úteis, de modo que elas podem não ser jamais postas sob questionamentos. Consequentemente, tudo o que sabem é considerado como "tudo" o que é necessário saberem para confrontar a doença.

Entretanto, diferentemente da ignorância, a incerteza, ou a dúvida, é capaz de conduzir as pessoas a adotarem outra postura diante de seus saberes. Quando as crenças e as certezas não dão mais conta da realidade, o indivíduo é acometido por certa insegurança e pela perplexidade. Surge, então, o desejo da verdade.

Ter algo no qual apoiar-se, adquirir certezas para pautar a própria existência, eis uma necessidade dos seres humanos. Daí que, para o homem confiar nos profissionais de saúde, naqueles profissionais que exercem na sociedade o papel de se ocuparem com o corpo dos indivíduos e com o corpo da população, é uma necessidade fundamental. Sem confiança não poderá haver consentimento aos conselhos e nem às recomendações que esses profissionais elaboram e fornecem quando estabelecem relações com as pessoas.

Mas, quando os conselhos e as recomendações desses profissionais são postas sob desconfiança, que efeitos colaterais podem ser esperados? Bem, a pergunta: "é assim mesmo, como dizes?", não é uma pergunta comum que emerge na relação entre médico e paciente, afinal, estamos numa sociedade em que se acredita nas instituições médicas, nos centros de pesquisas, e na qual se obtêm informações 24 horas por dia de jornais, rádios e televisões, e onde se encontram informações médicas em livrarias e bibliotecas especializadas, disponibilizadas em sites de fácil acesso.

Mas, se uma pessoa doente comparasse todas as informações recebidas e encontradas entre si, descobriria que elas não são unânimes, que exis- 
tem várias perspectivas, vários "mundos" diferentes e que dependem de fontes diversas de informações. Essa experiência, inevitavelmente, no mínimo, criaria dúvidas e incertezas. Mas, não é isso o que se observa na maioria das pessoas, e por isso não reconhecem que as informações recebidas são elaboradas com o propósito de dizerem a elas o que devem saber, o que podem e devem fazer. Ao confiarem nas palavras dos profissionais médicos, os "emissores de palavras que curam”, as pessoas sentem-se seguras e confiantes e, assim, não há incerteza porque há ignorância.

A perplexidade e a incerteza daquele que perguntou: "é de fato assim mesmo?", pode conduzilo a ir para além do que foi posto, além das certezas e das explicações dadas. Essa atitude de estranhamento ao que é familiar, diante das palavras e do mundo, tal como ambos se dão a ver, rompe com o mesmo, com o habitual; é uma certa maneira de profanar o que foi revestido de "sacralidade" e de "inquestionabilidade".

Ora, no meio científico (e no campo médico não é em nada diferente), o verdadeiro é o que funciona, ou o que dá conta da realidade. Verdade e realidade são apresentadas como coisas idênticas, e desfazer essa identidade é algo profundamente indesejável, ameaçador, dado que dá possibilidade para o surgimento das incertezas, as quais, por sua vez, fragilizam a relação entre curador e doente, entre os que exercem efeitos de mando e os que obedecem.

A concepção da verdade como sendo a correspondência entre realidade e pensamento, como algo que é mensurável, ou verificável, é que deu e dá possibilidades para a quase irrefutabilidade da dita Medicina Baseada em Evidências. Sendo considerado verdadeiro o que está conforme entre o que é pensado (as coisas) e os fatos. Sendo a evidência a visão intelectual do que é pensado, uma Medicina segura, digna de confiança, na qual as pessoas podem depositar suas seguranças, é a Medicina que não se apoia nas aparências, nem nas opiniões e tampouco nas ilusões de nossos órgãos dos sentidos. Por isso é que essa Medicina se arvora na condição de afirmar que seu discurso de verdade é universal e necessário, em contrapartida às opiniões, que variam de lugar para lugar, de sociedade para sociedade.

Poderíamos afirmar, olhando a sociedade contemporânea, que os diversos discursos de recomendações dietéticas, de atividades físicas, de uso de produtos, de emprego de tecnologias, de medicamentos (por exemplo: enunciados importantes em revistas e jornais, especializados ou não; em programas televisivos e radiofônicos; na internet), não necessariamente convencerão seus leitores ou ouvintes, e de que é igualmente possível que aqueles que são desprovidos do conhecimento médico sejam os mais susceptíveis de acreditarem nos mesmos; uma crença capaz de fazêlos não somente mudar de conduta, incorporando o que é apresentado como "certo" e "bom" para o corpo, como também de fazê-los consumidores desse discurso.

O consumo dessas informações, conselhos e recomendações criaria, entre os veículos e seus consumidores, uma relação do tipo provedor/ consumidor, nos moldes da sociedade de consumo. Dicas, informações, conselhos, tudo isso se tornou uma espécie de mercadoria, em torno da qual desenvolvem-se instrumentos, técnicas e habilidades para o seu repasse, sua difusão, seu emprego, capazes de modificar o modo pelo qual os indivíduos e a sociedade avaliam a vida. É na expectativa de que esses elementos sejam incorporados e que modifiquem as condutas das pessoas, que os “transmissores" desses conteúdos tornaram-se hábeis em produzir a verdade, em fazê-la circular e em persuadir os que a escutam ou a leem, de modo tal que a verdade transmitida seja tida como a mais importante regra, um décimo-primeiro mandamento, cujo seguimento é garantia de uma vida feliz: "Os discursos só adquirem o seu valor (e o seu sentido) na relação com um mercado, caracterizado por uma lei de formação dos preços particular: o valor do discurso depende da relação de forças que se estabelece, concretamente, entre as competências linguísticas dos locutores, entendidas simultaneamente como capacidade de produção e de apropriação e apreciação ou, por outras palavras, da capacidade que têm os diferentes agentes envolvidos na troca de impor os critérios de apreciação mais favoráveis aos seus produtos"13.

A relação entre os que proferem os discursos e seus ouvintes (consumidores) é uma relação, na perspectiva de Pierre Bourdieu ${ }^{13}$, mercadológica. Não diferindo de Baudrillard ${ }^{4}$, Bourdieu diz que a relação entre médico e doente, entre profissionais de saúde e a sociedade em geral, essas relações, todas elas, são atravessadas por variações de valor a depender da posição de poder que ocupam quem fala e quem escuta. Os critérios de apreciação dos produtos são estabelecidos pela competência ou legitimidade de seus artesãos.

"Devemos voltar ao início e perguntar, antes de qualquer coisa, por que alguém iria querer falar, escrever ou publicar" ${ }^{14}$. À pergunta de Lindsay Waters, podemos responder com Nietzs- 
che: falar, escrever ou publicar são modos da manifestação da Vontade de poder. Posto sob à luz desse conceito nietzschiano, esse querer publicar, escrever e falar é, em outras palavras, vontade de fixar o mundo, "Um mundo que nós podemos venerar, que é consoante ao nosso impulso venerador - que se comprova continuamente - pela condução do individual e do universal -: está é a concepção cristã, da qual nós todos proviemos"15.

Para Nietzsche, o escrever e toda a gramática são sintomas de um determinado estado fisiológico, é interpretar, e quem o faz são nossos afetos. "É a vontade de conservação do indivíduo, de uma comunidade, de uma raça, de um Estado, de uma igreja, de uma fé, de uma cultura"15. Nietzsche faz essa afirmação, não a partir da metafísica, mas da fisiologia animal; quem fala é o instinto de rebanho. "Ele quer ser senhor: daí o seu 'tu deves!'”. Como ele mesmo dirá: “De fato, é coisa da educação conduzir o membro do rebanho a uma determinada crença sobre a essência do homem: primeiro ela produz essa crença e exige, em consequência disso, 'veracidade"”'15.

Lindsay Waters, editor-chefe da Harvard University Press, publicou em 2004 um ensaio em que apela à proteção dos bons livros, os quais, segundo ele, estão se tornando escassos. Afirma: "Há um elo causal entre a demanda corporativa pelo aumento da produtividade e o esvaziamento, em todas as publicações, de qualquer significação que não seja gerar números"14.

Para Waters, as universidades em todo o mundo acolheram sem estranhamento métodos sofisticados de contabilidade para computar o trabalho de docentes e pesquisadores, assujeitandose à concepção de que só é real o que pode ser contado. Desde os anos de 1960, segundo ele, verifica-se que as universidades norte-americanas tornaram-se corporações, como qualquer corporação, cujas ações são negociadas nas bolsas de valores. "O aumento meteórico das publicações acadêmicas desde a década de 1960 até a década de 1990 explodiu violentamente, com certe$\mathrm{za}$, da mesma forma que os indicadores Dow Jones e NASDAQ. Agora é hora de parar e entender o quanto essa explosão é inimiga da vida da mente, porque o ensino e a escrita sérios tiveram de ser postos em posição secundária quando as publicações, por si mesmas, foram glorificadas"14.

Basta olharmos as avaliações que são impostas às universidades; mostram claramente que estas se tornaram, de fato, empresas. O típico professor universitário se parece cada vez mais com a figura retratada por Chaplin em seu Tem- pos modernos, trabalhando louca e insensatamente para produzir, para obter pontos, buscando garantir sua estabilidade, objetivando ser um pesquisador de "Nível 1". Ou seja, o objetivo da produção da verdade é fazê-la circular na expectativa de que esta exerça seus efeitos remodeladores das relações sociais, seus efeitos combustíveis dos processos de empregabilidade, da manutenção e elevação dos índices de produtividade intelectual de uma instituição ou nação.

\section{Considerações Finais}

Se levarmos em conta as investigações que Foucault fez acerca da biopolítica, não é em nada insensato afirmarmos que estamos diante de uma economia cuja moeda não é somente o conhecimento. Assistimos, dentro das instituições de ensino e pesquisa, o estabelecimento de um novo design, dentro do qual, por meio da informação e dos saberes produzidos, os intelectuais produzem maneiras de viver, sentidos de vida, produzindo e consumindo centenas de subjetividades.

Esse design é um novo modo de relação entre o capital e a subjetividade. Penetrou nas universidades e atingiu os mais infinitésimos capilares da existência de docentes e pesquisadores, mobilizando-os, pondo-os para trabalhar, explorando-os, produzindo uma plasticidade sem precedentes. Trata-se de subjetividades "vampirizadas", novos modos de viver em comércio. Vale, assim, a pergunta: "Que capacidade social de produzir o novo está disseminado por toda a parte, sem estar essa capacidade subordinada aos ditames do capital, sem ser proveniente dele nem depender de sua valorização?"16.

A invenção não é prerrogativa dos intelectuais, dos pesquisadores, das mentes geniais, nem monopólio exclusivo da ciência; ela é possibilidade de todo homem comum, em suas minúsculas variações. Todavia, a partir do momento em que os indivíduos são classificados por aquilo que escrevem, por aquilo que falam, pelo que publicam, temos o estabelecimento de um programa de engajamento moralizante. As publicações, longe de serem a materialização do que pensam os seus autores, são a confissão da moral que se impõe aos mesmos, às suas instituições, aos leitores e à sociedade.

Concordo com Waters, quando afirma que essa imposição sobre os docentes e pesquisadores universitários é um modo de inibir o pensamento. Foi instilado, dentro dos Departamentos, a obrigatoriedade de se manter um status 
quo, à custa de um disfarce de inovação do conhecimento. Para Waters, esses são os inimigos da esperança. É óbvio que Waters é um dos promotores da humanidade, entretanto, teve a coragem de dizer a seus pares: "não vamos mais fingir que todos estão interessados no livre desenvolvimento de ideias e na atividade acadêmica livre. Não vamos mais fingir que os acadêmicos são intelectuais públicos [...] Meu palpite é que pensamos algo mais ou menos assim: todos nós, que temos a imensa sorte de estar dentro deste sistema, sabemos que recebemos boas cartas nes- ta rodada; assim, simplesmente resolvemos ficar com essas cartas na mão e não jogar"14.

Afinal de contas, somos obrigados a produzir a verdade, somos pagos e bem recompensados por essa atividade, mas não somente: somos avaliados e classificados pela mesma verdade a que servimos, que cultuamos. Como uma divindade que veneramos e que tem sobre nós seus olhos, dia e noite, a verdade está à nossa espreita. Nós a nutrimos ao longo de milênios e, hoje, ela tornou-se nosso senhor, pronto para nos julgar e expressar seu veredicto.

\section{Referências}

1. Adams J. Risco. São Paulo: Editora Senac; 2009.

2. Beck U. Liberdade ou capitalismo: Ulrich Beck conversa com Johannes Willms. São Paulo: Editora UNESP; 2003.

3. Foucault M. Segurança, território, população. São Paulo: Martins Fontes; 2008.

4. Baudrillard J. A Sociedade de Consumo. Lisboa: Edições 70; 2007.

5. Nietzsche F. Genealogia da Moral: uma polêmica. São Paulo: Companhia das Letras; 2006.

6. Foucault M. Em defesa da sociedade. São Paulo: Martins Fontes; 2002.

7. Foucault M. A vontade de saber - História da Sexualidade I. Rio de Janeiro: Edições Graal; 2005.

8. Nottkins AL. De olho na Prevenção. Scientific American Brasil 2007; 5(59):38-45.

9. Jenkins DF. Construindo uma saúde melhor: um guia para a mudança de comportamento. Porto Alegre: Artmed; 2007.

10. Sfez L. A saúde perfeita: crítica de uma nova utopia. São Paulo: Unimarco editora, Edições Loyola; 1996.
11. Souza MA. Nietzsche asceta. Ijuí: Ed. Unijuí; 2009.

12. Foucault M. Segurança, território, população. São Paulo: Martins Fontes; 2008.

13. Bourdieu P. O que falar quer dizer: a economia das trocas linguísticas. Algés: DIFEL; 1998.

14. Waters L. Inimigos da esperança: publicar, perecer e o eclipse da erudição. São Paulo: Editora da UNESP; 2006.

15. Nietzsche F. A vontade de poder. Rio de Janeiro: Contraponto; 2008.

16. Pelbart PP. Vida capital: ensaios de biopolítica. São Paulo: Iluminaras; 2009.

Artigo apresentado em 26/03/2012

Aprovado em 01/05/2012

Versão final apresentada em 07/05/2012 